through a phase of mediocrity that is only just short of appalling. It is among journal articles that one best sees " the mounds of trivia that reach the light of day in expensive packaging " (26 July, p. 190). It is my belief that scientific interests would be best served if journal articles were to take the form of short letters outlining salient points of work done or findings made. At least $75 \%$ of journal material I see could be reduced by $50 \%$ without distortion of the message. The rest need not be published. There is too much of useless repetition, from author to author and from journal to journal. And yet new journals continue to appear.

When institutions begin to judge prospective staffers by the quality of their work, both published and unpublished, then might some reason come to the world of medical journalism.-I am, etc.,

\section{S. RAGBEER.}

\section{Department of Pathology,
University of the West Indies,
Kingston, Jamaica.}

\section{Educating Doctors}

SIR,-Sir George Pickering (16 August, p. 375 ) asks society to take a lesson from medicine and recognize " that education does not, and should not, and indeed cannot end with a university degree."

Medicine doubtless has something to be proud of in this respect, but in England and Wales it is still an offender in promoting premature specialization in school education. According to a survey published in the Todd report $^{1}$ only one-quarter of the medical students who completed their first year of study at English universities in 1966 had one or more nonscientific A levels-even when mathematics is included as a non-scientific subject. We may deduce from this that threequarters of the medical students entering medical school in that year had restricted their studies more or less exclusively to physics, chemistry, and biology since the age of 16 or even earlier.

Responsibility for this premature specialization cannot be laid at the door of the General Medical Council. As Sir George Pickering points out, the Council is most anxious that medical students should have a sound general education. The Council ${ }^{2}$ emphasizes the advantages to the student of taking English or a foreign language up to university entrance standard. It goes so far as to suggest that it is preferable that appropriate courses in physics and chemistry should be taken after entry to medical school rather than in the sixth form. In this it conflicts with the recommendation of the Todd report that "pre-medical" courses in physics and chemistry in medical schools should be done away with. As responsibility for the emphasis placed on physics, chemistry, and biology A levels does not rest with the General Medical Council it must lie with the universities and the medical schools themselves.

It would be interesting to know how many medical students entering university this month are able to write and speak their own language grammatically and with precision, and are able to read easily (let alone speak fluently) a living foreign language. It would also be interesting to know how many of them have more than an elementary know- ledge of the history of the culture in which they live, or of its system of economics and government.

In the new Medical School at Southampton we hope to take a step towards broadening the educational background from which medical students will be selected (21 June, p. 750). We will continue to insist on three A level passes, but only one scientific subject will be obligatory-namely, chemistry or the Nuffield physical sciences. At least one more subject must be selected from biology (or zoology), physics (where appropriate), or mathematics. The third may be offered from any subject approved by the university for matriculation. It thus becomes possible for a student to be admitted direct to the five-year medical course with, for example, an A level in chemistry, in mathematics, and in English, a classical subject, or a modern language. In addition we hope to follow the practice of other medical schools and give conditional acceptance to a limited number of candidates of unusual ability who have a combination of any three $\mathbf{A}$ levels other than those specified above. Such students must subsequently obtain an appropriate grounding in the physical sciences elsewhere prior to joining the medical course.

Until major changes take place in sixth form education this seems to be as far as it is possible for an individual medical school to go.-I am, etc., \section{The University,
Southampton. \\ REFERENCES \\ Report of Royal Commission on Medical Educa- tion, 1965-8, 1968. London, H.M.S.O. 1967. General Medical Council.
. Balical Education, \\ Depression Following Fluphenazine Treatment}

SIR,-The paper by Drs. R. de Alarcon and M. W. P. Carney (6 September, p. 564) raises important points on the relationship of depressive symptoms and the administration of phenothiazines in schizophrenia.

I have made a careful clinical assessment of 21 young schizophrenic patients under observation before the start of treatment, at the time of their first admission to hospital. Four were suffering with an acute melancholic reaction in addition to the primary symptoms of the disorder. In one patient the reaction appeared exacerbated by phenothiazines, but the patient improved when a course of electric convulsion therapy (E.C.T.) was given as well. Bleuler ${ }^{1}$ himself points out that acute melancholic reactions are the most common reactions occurring in the course of a schizophrenic illness.

Another group-the first 21 schizophrenic patients admitted in 1969-were reviewed. All have now been discharged. Ten were recorded as having depressive symptoms on admission. In six these persisted for more than a week after admission, but all were free of depression on discharge. All 21 received phenothiazines. However, three patients developed depressive symptoms within seven days of starting phenothiazines. Two patients on chlorpromazine were relieved when placed on perphenazine and trifluoperazine respectively. Those on thioridazine responded to E.C.T. Another patient became very confused on chlorpromazine and this ceased when trifluoperazine was substituted.

It would seem, therefore, that depressive symptoms, including melancholic reactions, are frequent in schizophrenia and can occur after the administration of phenothiazines other than fluphenazine. Critical attention such as that paid by Drs. Alarcon and Carney should be given to all phenothiazines to see how each compares in the apparent prevention of depression and even suicide. It must be emphasized that depressive reactions in schizophrenia can lead to suicide and that this perhaps, like the melancholic, is more likely to occur as treatment improves initiative before it relieves the mood disturbance.

Their plea that the mere administration of phenothiazines is not enough, and that in addition there is needed proper clinical supervision and community care, deserves the support of us all.-I am, etc.,

D. H. Marjot

Royal Victoria Hospital,

\section{REFERENCB}

1 Bleuler, E., Dementia Praecox or the Group of Schizophrenias, 1950, p. 208.
national Universities Press.

SIR,-I was interested to read Drs. $R$. de Alarcon and M. W. P. Carney's observations (6 September, p. 564) on the occurrence of severe depression in patients treated with fluphenazine enanthate or decanoate. However, it is well recognized that phenothiazines in general can precipitate episodes of depression, ${ }^{12}$ and one would not have expected fluphenazine to be an exception.

Unfortunately, we have no sure way of predicting which patients are liable to develop phenothiazine-induced depression, which is another good reason for maintaining a scrupulous and extended follow-up on all patients having long-term phenothiazines, whether orally or by depot injection. In my experience, some patients with schizoaffective illnesses do very well on maintenance injections of fluphenazine decanoate in combination with long-term oral lithium carbonate.-I am, etc.,

M. F. A'BROOK. Belmont Hospital,
Sutton, Surrey.

\section{REFERRENCES}

Pollitt, J., Depression and its Treatment, 1965. London. Hepression and

Sargant, iW and Slater, E., An Introduction to

Physical Methods of Treatment in Psychiatry,
1963,4 th edition. Edinburgh, Livingstone.

\section{Respirators in Respiratory Failure}

SIR,-I was sorry to read that Dr. W. Howlett Kelleher (30 August, p. 528) was astonished to note the views I had expressed at the Annual Scientific Meeting of the B.M.A. at Aberdeen (19 July, p. 165). Some of his astonishment may be due to the fact he was not present at the meeting, and I am sure he will understand that sententious remarks made in a debate when quoted out of context often lead to misconceptions. The title of the symposium at which I spoke was that of the management of respiratory failure, and I made it very clear that in my view the cabinet respirator has no place in the treatment of acute respiratory failure. At the 